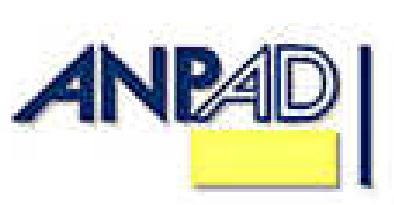

Disponível em

http://www.anpad.org.br/rac

RAC, Curitiba, v. 14, n. 1,

pp. 172-188, Jan./Fev. 2010

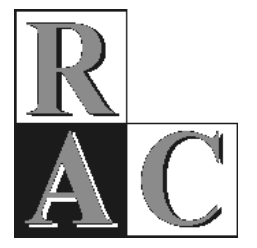

Casos de Ensino em Administração:

\title{
A Morte Simbólica em Mudanças Organizacionais: o Caso do Banco do Brasil
}

\author{
Symbolic Death in Organizational Changes: the Banco do Brasil Case
}

Ana Maria Roux César *

Doutora em Administração de Empresas pela FEA/USP.

Professora do Programa de Mestrado Profissional em Controladoria/UPM, São Paulo/ SP, Brasil.

*Endereço: Ana Maria Roux César

Rua Apinagés, 1752, apto. 41, São Paulo/SP, 01258-000. E-mail: rouxcesar@uol.com.br

Copyright @ 2010 RAC. Todos os direitos, inclusive de tradução, são reservados. É permitido citar parte de artigos sem autorização prévia desde que seja identificada a fonte. 


\section{INTRODUÇÃO}

Em 1998 o Banco do Brasil estava ajustando sua política de negócios, após a grande reestruturação que ocorreu nos anos de 1995 e 1996. Dentre as mudanças havia o Plano de Demissão Voluntária [PDV], proposto para enxugar o quadro de pessoal. Era um momento de grande apreensão, por parte dos funcionários. Os que haviam ficado no Banco sentiam que 'os ventos não eram mais os mesmos'. Os que ingressavam não entendiam como os funcionários mais antigos podiam estar tão apegados a um passado que já não existia. Na época, um antropólogo estimou em 10 anos o tempo necessário para o Banco mudar sua cultura. Mas o Banco não tinha esse tempo. Como diminuir o apego ao passado, fazendo com que as pessoas olhassem principalmente em direção a um novo cenário?

Esta situação vivida pelo Banco do Brasil tem-se repetido em outras empresas. Todas têm um ponto em comum: promoveram rupturas internas, seja por reestruturação, seja por processos de fusão ou aquisição. O que se viu no Banco do Brasil, 10 anos atrás, se repete de maneira quase idêntica em outras instituições. A pergunta que fica é: em situações de mudança semelhantes à ocorrida no Banco do Brasil, pode-se fazer alguma coisa para que os funcionários percebam essas situações como ganho, ao invés de perda pessoal?

\section{Um Breve Histórico do Banco do Brasil}

O Banco do Brasil foi a primeira instituição financeira do país, tendo sido fundado em 1808 por D. João VI, constituindo-se, em 1809, no quarto emissor de moeda no mundo (só havia bancos emissores na Suécia, Inglaterra e França).

Suas primeiras atividades estavam fortemente atreladas à movimentação do tesouro da Casa Real, o que levou o Banco a passar por uma série de instabilidades quando a família real deixou o Brasil e, conseqüentemente, retirou seu capital do Banco. Apesar disto, o Banco se manteve até 1829, quando foi promulgada uma Lei que o extinguiu, em face das acusações de que, enquanto emissor de moeda, contribuía para a desvalorização do meio circulante.

Em 1833 o Banco do Brasil voltou à cena, com nova lei que o reinstalava, mas que ainda previa ingerência do Governo em suas atividades. A situação se alterou a partir de 1851, quando o Visconde de Mauá e outros investidores fundaram outro banco, batizando-o também de Banco do Brasil; este segundo banco, que tinha um capital altíssimo para a época (dez mil contos de réis), assimilou o primeiro Banco do Brasil e se fundiu ao Banco Comercial do Rio de Janeiro, mantendo o nome original. Assim, em 1854, o Banco do Brasil começou a funcionar sem interveniência do Governo em suas operações, instalando-se definitivamente como banco comercial, embora ainda mantivesse forte ligação com o Governo, por ser emissor de moeda, papel que manteve até 1866, quando se transformou num instituto de depósitos, descontos e empréstimos.

Nas décadas subseqüentes, o Banco assumiu o papel de banco de fomento econômico, destinando recursos para agricultura e indústria; também ocupou papel de destaque na política de incentivo ao comércio internacional, o que se consolidou com a criação de sua Carteira de Comércio Exterior [CACEX] em 1953.

\section{A Perda da Conta Movimento}

O Banco se manteve ao longo dos anos, enquanto agente de transformação, com grande peso no cenário nacional em termos de negociações rurais, industriais e comerciais. Como empresa de capital misto, seu maior acionista era o Governo Federal, o que lhe dava, ao longo de sua existência, o caráter de agente financeiro do governo. Esta situação se alterou em 1986, quando o Banco deixou de ser detentor da Conta Movimento, mantida pelo Banco Central. Esta conta lhe garantia suprimento 
automático de recursos e sua extinção provocou mudança radical nos negócios do Banco: agora precisava captar recursos em segmentos de mercado para os quais não tinha nenhuma experiência.

Esta data marcou a primeira grande mudança do Banco, que se estabeleceu, a partir de então, como conglomerado financeiro, abrindo no ano seguinte quatro subsidiárias: BB Financeira, BB Leasing, BB Corretora de Seguros e Administradora de Bens, e BB Administradora de Cartões de Crédito. Mas grandes mudanças no Banco do Brasil viriam pela frente, ocasionadas pelas mudanças tecnológicas, que criaram novos modelos para a atuação dos Bancos.

\section{O Panorama Bancário no Final do Século XX}

O sistema financeiro brasileiro sofreu profundas alterações nos últimos trinta anos do século XX. O setor especializou-se por segmentos, fazendo com que cada instituição financeira tivesse papel especialmente definido no sistema. Houve concentração no setor bancário, com grande número de fusões e incorporações. Além disto, o sistema financeiro sofreu a influência de diversas forças, que direcionaram ou alteraram os rumos dos eventos, como questões sociopolíticas, regulacionais, econômicas, mercadológicas e tecnológicas.

Os resultados da reforma bancária e da atuação dessas outras forças foram, dentre outras, as seguintes: modernização do sistema financeiro, melhor qualidade dos serviços prestados, internacionalização do crédito, maior facilidade de controle sobre as instituições financeiras e o desenvolvimento nacional na área de tecnologia da informação.

Dentre as principais mudanças decorrentes da implantação de tecnologia na área bancária aponta-se este elenco: geração de sistemas on-line, que possibilitou processamento centralizado em tempo real e o banco de dados relacional (relational data base), que reúne as informações necessárias e abrangentes para o relacionamento com o cliente; a digitalização de assinaturas; o emprego de sistemas especialistas, que permitem simulações financeiras e avaliação de riscos em empréstimos.

Em relação ao autoatendimento, foram disponibilizados dois tipos de serviço: nas próprias agências, em áreas com terminais para clientes, ou fora das agências, em quiosques ou espaços com caixas automáticos. Também foram instalados os serviços de atendimento on-line, em que o cliente pode fazer todas as operações que não envolvam saque ou depósito de dinheiro, atuando em bases remotas. Apareceu a oferta de serviços on-line, que antes eram restritos ao atendimento pessoal ou remessa postal, como liberação de dinheiro na conta dos clientes, disponibilização de extratos e saldos de contas correntes e demais operações, emissão de talões de cheque, recebimento de contas diversas, transferência de fundos e aplicações financeiras pré-autorizadas. Em outras palavras, o cliente passou a interagir menos com funcionários do banco para suprir suas necessidades financeiras do dia a dia.

Quanto aos funcionários, com as mudanças no atendimento bancário, cada vez menos lhes era exigido que fossem atendentes. Em tempos virtuais, os funcionários deveriam cumprir o que as máquinas não faziam: vender produtos e serviços, atuar como consultores financeiros e conseguirem a fidelização dos clientes à instituição e aos seus produtos e serviços. Os papéis típicos de um bancário foram drasticamente alterados: de funções burocráticas, em posturas reativas, para funções mais agressivas associadas à venda, exigindo atitudes proativas.

A tecnologia da informação que, por um lado, vinha sendo apontada como um dos fatores críticos de competitividade na área bancária (visto que, a partir da mesma, se prestam serviços baseados em informações que dependem da redução de tempos e de custos de processamento), por outro lado vinha exigindo novos padrões de relacionamento entre prestador de serviço e cliente, fosse este interno ou externo. Esta exigência encontrou obstáculos, desde resistências de caráter político e social, até dificuldades psicológicas para sua aceitação. Havia até aqueles que alegavam que essas tecnologias podiam ser vistas como geradoras de desumanização, como instrumento de dominação e de concentração de capital. 
Essas mudanças no padrão de atendimento ao cliente geraram grandes reestruturações internas nos Bancos que atuavam no Brasil. E, do ponto de vista dos funcionários, parece que a tarefa de se ajustar ao novo papel exigido não era nada fácil.

\section{O Ajuste do Banco do Brasil à Mudança de Cenário no Setor Bancário}

O Banco entrou na década de 90 precisando reestruturar sua atuação, para se manter competitivo. A situação se agravou com o advento do Plano Real em 1994, vez que, com a tendência de estabilização monetária, os bancos perderam a facilidade dos ganhos obtidos pela aplicação de recursos no mercado financeiro.

Neste contexto, em março de 1995, assumiu uma nova diretoria no Banco. Esta trazia uma série de propostas para modernização e aumento da competitividade da empresa, acreditando que o Banco não podia mais trabalhar sem uma visão clara de que era um banco comercial, a despeito de ser um banco governamental com uma responsabilidade social. Esta nova diretoria sinalizava claramente que o Banco precisava dar lucro e remunerar seus acionistas, tanto na figura do Governo Federal quanto na dos acionistas minoritários.

Para conciliar o desafio que se impunha à empresa naquele momento, a direção do Banco propôs uma série de medidas que pudessem garantir a sobrevivência da empresa em ambientes de alta competitividade. Fez investimentos em atualização tecnológica, bem como reviu toda a rede de distribuição do Banco. Buscou adaptar-se às exigências do mercado, delineando nova arquitetura organizacional, com nove unidades de negócios e cinco unidades de função, visando obter maior flexibilidade e rapidez de resposta. Criou nova política para gestão de ativos, com campanhas para recuperação de créditos e maior captação de recursos. Lançou um plano de demissão voluntária, fato considerado inédito na história do Banco, desligando 14.000 funcionários e sinalizando para os remanescentes que a empresa não era mais a mesma.

Apesar de todas estas medidas o Banco fechou o ano de 1996 com um prejuízo histórico, na ordem de quase $\mathrm{R} \$ 8$ bilhões de reais, prejuízo este fortemente impactado pelas provisões para créditos de liquidação duvidosa. Entretanto, após medidas rigorosas para ajuste, no ano seguinte o Banco voltou a apresentar lucro na ordem de $\mathrm{R} \$ 573$ milhões.

Em 1999 o Banco fez novos ajustes organizacionais, criando uma Unidade de Controles Internos em atendimento às disposições da Resolução 2.554 do Conselho Monetário Nacional, voltada para controles internos. Esta Unidade atuava em conjunto com outras unidades de controle, como Contadoria e Controladoria.

Após esse período, o Banco se expandiu via Internet e, em face da sua atuação em diversas áreas, registrou um Lucro Líquido de cerca de $\mathrm{R} \$ 980$ milhões, com retorno de $12 \%$ sobre o Patrimônio Líquido.

\section{A Percepção dos Funcionários em Relação às Mudanças - a Visão do Banco}

Por volta de 1999, quando o Banco do Brasil fez novos ajustes, os funcionários já deveriam estar preparados para aceitá-los. Eles já haviam absorvido os impactos da primeira grande mudança, que ocorreu nos anos de 1995 e 1996.

Logo após o lançamento do Programa de Demissão Voluntária [PDV], em 1995, os psicólogos do quadro do banco desenvolveram uma série de entrevistas com os funcionários que optaram por sair da empresa, e com aqueles que resolveram ficar. A posição desses últimos era a seguinte: alguns funcionários temiam o novo; outros achavam que haviam sido abertas possibilidades de desenvolvimento profissional; outros percebiam que o Banco os chamava para fazer cursos, e que a participação representava 'um remédio que iria curar' seu obsoletismo, evitando a verdadeira ruptura com a organização: a demissão. 
De modo geral, os psicólogos do quadro do banco percebiam muito apego à situação anteriormente vivida, considerada por vários funcionários como melhor, mais estável. Havia funcionários que não 'digeriam' as mudanças, notadamente a exigência de novos papéis, pois nas agências era fortemente incentivado o papel de vendedor de produtos e serviços do Banco. Isto era especialmente difícil para os funcionários que viveram o Banco antes da perda da Conta Movimento, época em que se dizia: "o Banco não precisa do cliente". Isto já havia mudado há muitos anos, mas até então ninguém havia sido punido, se não cumprisse o papel esperado. O PDV sinalizou que o Banco estava mudando suas exigências em relação aos funcionários. Não era mais o 'paizão', forma como muitos empregados percebiam a organização.

\section{A Percepção dos Funcionários em Relação às Mudanças - a Visão do Pesquisador Externo}

Três anos após o PDV um pesquisador externo autorizado pelo Banco desenvolveu pesquisa para detectar como andavam o estado de ânimo e a saúde dos funcionários do Banco do Brasil, bem como para avaliar qual era a percepção que tinham em relação às mudanças, concentrando-se em três dimensões: Pertinência à Empresa, Afiliação a Grupos e Práticas de Recursos Humanos (ver Anexo 1). Sua pergunta era: os funcionários do Banco sentiam que tinha havido ganho ou perda com a reestruturação que entrou em vigor? O pesquisador estabeleceu critérios para julgamento de ganho ou perda e utilizou uma escala de 6 pontos para que os respondentes apontassem o nível percebido de ganho ou perda em relação a indicadores de cada uma das três dimensões estudadas (ver escala e os critérios de julgamento nos Anexos 2 e 3 ).

$\mathrm{Na}$ época não era possível para o pesquisador fazer um censo entre os funcionários do Banco, em face do seu grande número (perto de $70 \mathrm{mil}$ ). Assim, escolheu estudar os funcionários do Estado de São Paulo, o que não era pouco, pois em meados de 1998, o Banco do Brasil contava com 11.485 funcionários lotados no Estado de São Paulo. Entre esses funcionários, o pesquisador destacou uma amostra de 400 pessoas, composta em sua maioria $(90,5 \%)$ por pessoas que vinham exercendo funções comissionadas: cargos de chefias ou cargos técnicos de nível superior. Todos os pesquisados estavam participando de ações de treinamento dentro de uma base da Universidade Corporativa localizada em São Paulo: naquela época, essa base era nomeada Centro de Formação. O pesquisador considerou que esse grupo deveria ter uma visão mais otimista sobre o Banco, pois afinal o Banco estava investindo em seu desenvolvimento profissional, talvez porque eles fossem os responsáveis por equipes de trabalho (médias gerências, analistas e auditores) e representassem o elo entre o segmento estratégico e o operacional da empresa.

Analisando os dados encontrados, o pesquisador externo ao Banco detectou que, três anos após as grandes mudanças, especialmente após a introdução do PDV, perto de um quarto dos funcionários que responderam à pesquisa $(23,9 \%)$ tinha um perfil predominante de percepção de perda; os funcionários achavam que o Banco de antes era melhor e que não haviam ganho nada com as mudanças (ver Anexos 4, 5 e 6$)$.

A percepção de perda estava concentrada nos seguintes indicadores: estabilidade no emprego; nível salarial; valorização social por ser funcionário da empresa; clima de alegria e bom humor nas equipes de trabalho; imagem dos funcionários da empresa na comunidade; espírito de corpo dos funcionários da empresa; plano de assistência médica; apoio da equipe em situações de crise pessoal; orgulho por ser funcionário da empresa.

Pouco mais de um décimo dos funcionários $(14,2 \%)$ tinha perfil de ganho, ou seja, achava que as mudanças do Banco tinham gerado ganhos pessoais. A percepção de ganho concentrava-se em: sentimentos de lealdade à empresa; união da equipe em situações de mudança; apoio da equipe para destaque profissional de seus integrantes; identificação com a empresa; cooperação dentro da equipe de trabalho; critérios para avaliação de desempenho funcional; idéias compartilhadas dentro da equipe de trabalho; possibilidade de ascensão profissional; participação em treinamentos na empresa. 
Todos os demais respondentes encontravam-se no que se considerou Zona Neutra, ou seja, havia uma situação ambivalente, na qual havia percepção de ganhos e perdas, simultaneamente. Para chegar a esse perfil o pesquisador considerou aqueles que haviam respondido predominantemente usando os pontos 3 (pouca perda) e 4 (pouco ganho) da escala.

Considerando-se os perfis de perda em cada uma das dimensões propostas pelo pesquisador encontraram-se: 35,4\% de perda na dimensão Pertinência à Empresa; 23,8\% em Afiliação a Grupos; e 15,8\% em Práticas de Recursos Humanos. Encontrava-se maior porcentagem de perfis de ganho na dimensão Afiliação a Grupos $(19,6 \%)$ e maior porcentagem de perfis Neutros em Práticas de Recursos Humanos $(74,5 \%)$.

O maior nível de percepção de perda, na dimensão Pertinência à Empresa, que se referia à identificação do funcionário com o Banco, sugeria que estava havendo perda de envolvimento psicológico com a empresa, o que se podia refletir em perda de crenças e atitudes favoráveis a ela. Isto podia levar a um desvio em relação aos comportamentos esperados pela empresa, ocasionando perda de desempenho. Os dados também sugeriam que os funcionários não entendiam bem a qual empresa pertenciam, já que os valores do Banco se haviam alterado.

$\mathrm{O}$ retrato tornou-se mais sombrio, quando o pesquisador analisou o estado de ânimo dos funcionários que responderam à pesquisa. Foi-lhes apresentado um quadro com vários sentimentos (Anexo 7) e solicitado que escolhessem os 10 sentimentos que estavam mais presentes em seu estado de ânimo nos últimos 12 meses. Os sentimentos mais escolhidos em cada posição (Anexo 8) mostram que havia forte predomínio de sentimentos negativos, como ansiedade, medo, fadiga, vazio, frustração. Como sentimentos positivos apareciam coragem e esperança. O estado de ânimo predominante mostra que havia pessoas que sofriam, mas que tinham esperança de melhora. Chamava a atenção o fato de que os sentimentos positivos apontados sinalizavam, de alguma forma, a dificuldade para enfrentar as mudanças. Um estado de ânimo mais negativo aparecia entre funcionários de média gerência que detinham entre 13 e 22 anos de empresa; tratava-se de pessoas do segmento tático, que tinham alcançado postos de gestão e que eram responsáveis pelas rotinas de implementação de novas tecnologias ou de novas práticas de gestão de negócios. Eram os funcionários que deveriam levar a termo a transformação do Banco do Brasil. Mas como eles poderiam exercer um papel motivacional para suas equipes, se eles próprios estavam sem coragem para serem 'efervescentes'? Como essas pessoas poderiam contribuir para a otimização do Capital Humano, visando ao aumento de competitividade, se eles não se sentiam mais 'vestindo a camisa da casa'?

O estudo não parou por aí. O pesquisador também buscou identificar-se entre os funcionários que responderam à pesquisa; havia a presença de sintomas somáticos relacionados ao estresse e que são comuns em situações subseqüentes à experiência de perda (estados de luto). O Anexo 9 apresenta uma lista dos sintomas que foram disponibilizados para que os funcionários apontassem os mais frequentes nos últimos doze meses anteriores à data da pesquisa.

Os sintomas mais presentes foram insônia (escolhido por 56\%), dores de cabeça (52\%), aumento de peso (38\%), nó na garganta (34\%), suspiros (34\%), azia (30\%), palpitações (26\%), queda de cabelos (25\%), respiração curta (22\%), boca seca e boca amarga (16\%) e cãibras (14\%). O aparecimento desses sintomas num período de transição, entre o antigo e o novo Banco, podia ser indicador de um estado de luto não elaborado.

Para finalizar sua análise, o pesquisador testou um modelo de interação das dimensões estudadas, para ver como uma dimensão poderia afetar a outra. O pesquisador considerou em sua análise duas dimensões novas. A uma delas deu o nome de Senioridade, que correspondia ao tempo de Banco, tempo de exercício da função na qual o funcionário estava lotado e idade do respondente. À outra dimensão criada foi dado o nome de Saúde e incluía o estado de ânimo do funcionário, a presença de sintomas somáticos relacionados ao estresse e à vivência de alegria e bom-humor nas equipes de trabalho: este indicador estava originalmente na dimensão Afiliação a Grupos. 
As correlações encontradas (Anexo 10) davam pistas importantes para o desenvolvimento de ações a serem propostas para que houvesse mudanças principalmente nas dimensões Afiliação a Grupos (que refletia a percepção de ganho ou perda do funcionário em indicadores associados ao trabalho em equipe) e Pertinência à Empresa (que refletia a percepção de ganho ou perda do funcionário em indicadores associados ao comprometimento e à identificação do funcionário à empresa).

A partir dessas correlações, o pesquisador propôs um modelo de atuação, conforme Anexo 11, com ações para intervenção sobre o estado psicológico dos funcionários (eixo superior do modelo) e para conscientização sobre as mudanças que ocorreram no ambiente organizacional (eixo inferior do modelo). Essas duas linhas de ação deveriam ocorrer simultaneamente. Segundo o pesquisador, a implantação do primeiro eixo, de maneira isolada, seria vazia de significados para os envolvidos, pois não apresentaria proposta concreta para melhora de desempenho; a do segundo eixo, isoladamente, não encontraria eco junto a pessoas que estavam atemorizadas e resistentes a qualquer tipo de mudança.

\section{Dez Anos Depois - o Banco no Século XXI}

A partir de 2001 o Banco do Brasil se consolidou como Banco Múltiplo, tendo papel igual aos demais bancos do sistema bancário brasileiro. Neste mesmo ano, o Banco sofreu nova alteração na configuração de seu Conglomerado, dividindo a Diretoria Executiva em dois níveis: O Conselho Diretor, composto pela Presidência e Vice Presidências, e demais diretores. O Conselho Diretor ficou com o foco nas ações estratégicas e no relacionamento institucional, enquanto os diretores passaram a responder pela direção da condução dos negócios. Criaram-se comitês e subcomitês para permitir a descentralização do processo decisório; e o Banco se reestruturou em quatro entidades organizacionais: Diretoria, Unidades de Assessoramento, Unidades de Função e Unidades Estratégicas de Negócios. Com este modelo o Banco passou a considerar quatro pilares negociais: Atacado, Varejo, Governo e Recursos de Terceiros.

O Banco chegou a 2007 com mais de dez empresas coligadas que atuam nos ramos de saúde, seguros, previdência privada, capitalização, tecnologia e cartões de crédito. Está estruturado com nove Vice-Presidências e vinte e seis Diretorias. Conta com mais de 90.000 colaboradores, tem 124,6 milhões de correntistas, cerca de 15 mil pontos de atendimento em mais de 3.000 cidades, está presente em 22 países e é a maior instituição financeira do país (dados de maio/2007). Em 2004 o Banco ganhou o prêmio oferecido pela Associação Brasileira das Companhias Abertas, por se destacar na elaboração de seus relatórios anuais, mostrando transparência e qualidade nas informações contidas neles. Foi a única instituição brasileira a ganhar o prêmio.

No segundo trimestre de 2007 o Banco atingiu os seguintes números: ativos de $\mathrm{R} \$ 333$ bilhões; RSPL de 29,4\%; carteira de crédito de R 145 bilhões; lucro recorrente de 1,5 bilhão; dividendos de R \$ 427 milhões. O Banco tem assumido o papel de agente financeiro de Estados da Federação, como é o caso dos Estados da Bahia e de Minas Gerais.

No final, parece que as pessoas que atuavam no Banco acabaram dando conta do recado. Não se sabe se o modelo proposto pelo pesquisador foi implantado; mas, considerando-se as relações encontradas em sua pesquisa, seria viável aplicá-lo em outras empresas, para minimizar a percepção de Perda pessoal em situações de mudança. 


\section{ANEXOS}

Anexo 1

Indicadores das Dimensões Pesquisadas

\begin{tabular}{ll}
\hline DIMENSÕES & INDICADORES \\
\hline Práticas de Recursos Humanos & Estabilidade no emprego \\
& Possibilidade de ascensão profissional \\
& Nível salarial \\
& Plano de assistência médica \\
& Participação em programas de profissionalização \\
& Critérios para avaliação de desempenho profissional \\
Afiliação a grupos & Cooperação dentro da equipe de trabalho \\
& Apoio da equipe em situações de crise pessoal \\
& Idéias compartilhadas dentro da equipe de trabalho \\
& União da equipe em situações de ameaça profissional \\
& Apoio da equipe para destaque profissional de seus \\
& integrantes \\
& Clima de alegria e bom humor na equipe de trabalho \\
Pertinência à empresa & Orgulho por ser funcionário da empresa \\
Sentimento de lealdade à empresa & Identificação com a empresa: vestir a camisa \\
& Espírito de corpo dos funcionários da empresa \\
& Valorização social por ser funcionário da empresa \\
Imagem do funcionário da empresa na comunidade \\
\hline
\end{tabular}

Nota. Legenda: o quadro apresenta os indicadores de cada uma das dimensões pesquisadas. Pode-se ver, ao longo do texto que apresenta o caso, quais desses indicadores foram percebidos como ganho ou como perda pelos funcionários que vivenciaram o processo de mudança no BB.

Anexo 2

Critérios para Julgamento Enquanto Ganho ou Perda

\begin{tabular}{ll}
\hline Alternativas para ganho & Alternativas para perda \\
\hline Melhoria de condição & Piora de condição \\
Aumento de nível & Diminuição de nível \\
Maior possibilidade & Menor possibilidade \\
Maior intensidade & Menor intensidade \\
Maior clareza & Menor clareza \\
Maior apoio & Menor apoio \\
Maior reconhecimento & Menor reconhecimento \\
\hline
\end{tabular}

Nota. Legenda: esses critérios serviam para que o funcionário que respondia à pesquisa se posicionasse, ou melhor, compreendesse a situação de perda ou de ganho em relação aos indicadores mostrados no Anexo 1. 
Anexo 3

Escala Utilizada pelo Pesquisador

\begin{tabular}{cccccc}
\hline $\mathbf{1}$ & $\mathbf{2}$ & $\mathbf{3}$ & $\mathbf{4}$ & $\mathbf{5}$ & $\mathbf{6}$ \\
\hline Excessiva perda & Muita perda & Pouca perda & Pouco ganho & Muito ganho & Excessivo ganho \\
\hline
\end{tabular}

Nota. Legenda: essa escala era apresentada junto com os níveis de análise mostrados no Anexo 2. Por exemplo, o funcionário que desse uma nota 1 ao nível salarial estaria considerando que houve uma excessiva perda (uma extrema diminuição de nível) de salário.

Anexo 4

Práticas de RH: Predominância de Escolha enquanto Ganho ou Perda

\begin{tabular}{|c|c|c|c|}
\hline Indicador & $\%$ Ganho & $\%$ Perda & Moda \\
\hline Estabilidade no emprego & & 83,9 & 2 \\
\hline Possibilidade de ascensão profissional & 70,2 & & 5 \\
\hline Nível salarial & & 75,3 & 1 \\
\hline Plano de assistência médica- & & 57,6 & 3 \\
\hline Participação em programas de profissionalização/treinamento & 82,7 & & 5 \\
\hline Critérios para avaliação de desempenho funcional & 67,1 & & 4 \\
\hline
\end{tabular}

Nota. Legenda: o Anexo apresenta os percentuais dominantes de escolha em cada um dos indicadores da dimensão Práticas de Recursos Humanos. Por exemplo, o indicador estabilidade no emprego teve $83,9 \%$ das respostas no nível de percepção de perda, sendo 2 a resposta mais presente, que significa percepção de muita perda.

Anexo 5

Afiliação a Grupos: Predominância de Escolha enquanto Ganho ou Perda

\begin{tabular}{|c|c|c|c|}
\hline Indicador & \% Ganho & $\%$ Perda & Moda \\
\hline Cooperação dentro da equipe de trabalho - V17 & 62,7 & & 4 \\
\hline Apoio da equipe em situações de crise pessoal - V20 & & 56,6 & 4 \\
\hline Idéias compartilhadas dentro da equipe de trabalho - V23 & 68,2 & & 4 \\
\hline União da equipe de trabalho em situações de mudança-V26 & 53,1 & & 4 \\
\hline Apoio da equipe para destaque profissional de seus integrantes-V29 & 54,6 & & 4 \\
\hline Clima de alegria e bom humor na equipe de trabalho - V32 & & 70,8 & 2 \\
\hline
\end{tabular}

Nota. Legenda: idem Anexo 5. 
Anexo 6

Pertinência à Empresa: Predominância de Escolha enquanto Ganho ou Perda

\begin{tabular}{lccc}
\hline \multicolumn{1}{c}{ Indicador } & \% Ganho & \% Perda & Moda \\
\hline Orgulho por ser funcionário da empresa - V16 & & 54,0 & 4 \\
Sentimentos de lealdade à empresa - V19 & 50,1 & 3 \\
Identificação com a empresa: vestir a camisa -V22 & 60.0 & & 4 \\
Espírito de corpo dos funcionários da empresa- V25 & & 59,9 & 4 \\
Valorização social por ser funcionário da empresa - V28 & & 74,2 & 2 \\
Imagem dos funcionários da empresa na comunidade - V31 & & 64,0 & 2 \\
\hline
\end{tabular}

Nota. Legenda: idem Anexo 6.

Anexo 7

Sentimentos Apresentados para Composição do Estado de Ânimo dos Funcionários

\begin{tabular}{ccc}
\hline Alegria & Ruptura & Abandono \\
\hline Displicência & Ânimo & Fadiga \\
Realização & Desprezo & Calma \\
Tristeza & Vazio & Ansiedade \\
Amor & Inquietação & Disposição \\
Medo & Harmonia & Opressão \\
Aprovação & Frustração & Desânimo \\
Otimismo & Plenitude & Ódio \\
Esperança & Liberdade & Paz \\
Coragem & Prazer & Pessimismo \\
\hline
\end{tabular}

Nota. Legenda: este quadro era apresentado aos respondentes para que escolhessem, entre os 30 sentimentos os 10 que estavam mais frequentemente presentes em seu estado de ânimo. Havia 15 pares: para cada sentimento positivo era apresentado também seu antagônico, como, por exemplo, alegria e seu antagônico, tristeza. Os sentimentos eram disponibilizados de forma aleatória no quadro.

Anexo 8

Sentimentos Mais Escolhidos do Primeiro ao Décimo Posto (Moda em Cada Posição)

\begin{tabular}{cccccccccc}
\hline P1 & P2 & P3 & P4 & P5 & P6 & P7 & P8 & P9 & P10 \\
\hline ansiedade & Inquietação & ansiedade & ansiedade & coragem & fadiga & ansiedade & fadiga & fadiga & esperança \\
\hline
\end{tabular}

Nota. Legenda: Os funcionários deveriam escolher, num conjunto de sentimentos (Anexo 7), quais os mais presentes em seu estado de ânimo nos últimos 12 meses anteriores à pesquisa, colocando em ordem de frequência ( $\mathrm{P} 1$ - $\mathrm{o}$ primeiro mais frequente, P2 - o segundo mais freqüente, e assim sucessivamente até o P10). Vê-se que, entre os sentimentos escolhidos, aparece um sentimento positivo na quinta posição (coragem) e no outro na décima posição (esperança). O estado de ânimo dominante, representado pelo conjunto dos sentimentos, é negativo, mostrando alta carga de ansiedade, inquietação e fadiga; os sentimentos positivos oferecem suporte para o enfrentamento deste estado de ânimo, pois coragem incita o sujeito a ter força para o enfrentamento, e esperança, para não desistir. 
Anexo 9

Sintomas Somáticos Presentes em Estados de Estresse e Luto

\begin{tabular}{llll}
\hline insônia & boca amarga & perda de peso & náuseas \\
\hline azia & respiração curta & palpitações & aumento de peso \\
cãimbras & nó na garganta & queda de cabelos & boca seca \\
vômitos & suspiros & tremores & dores de cabeça \\
\hline
\end{tabular}

Nota. Legenda: este quadro era apresentado para que os respondentes marcassem quantos destes sintomas ele tinha frequentemente. No questionário disponibilizado aos respondentes não havia menção da associação dos mesmos com estados de estresse e luto.

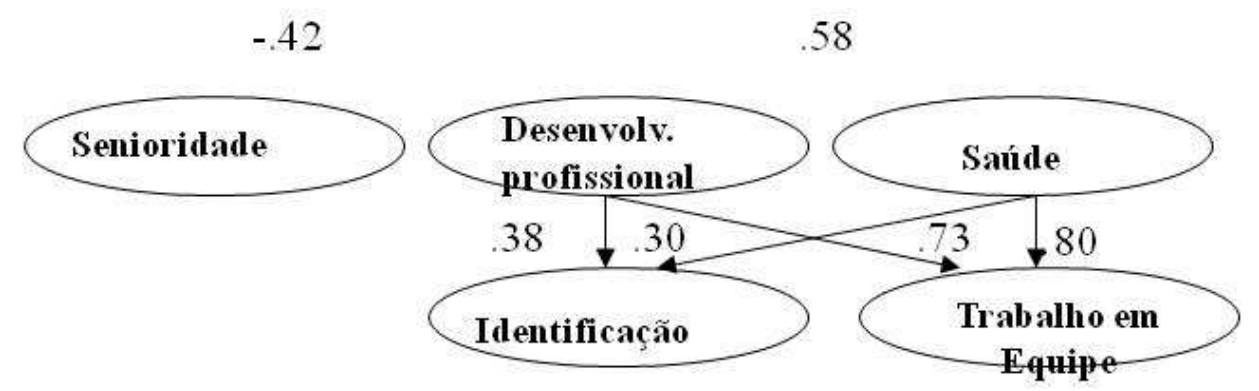

Anexo 10: O Modelo de Relacionamento Encontrado pelo Pesquisador entre as Dimensões Pesquisadas

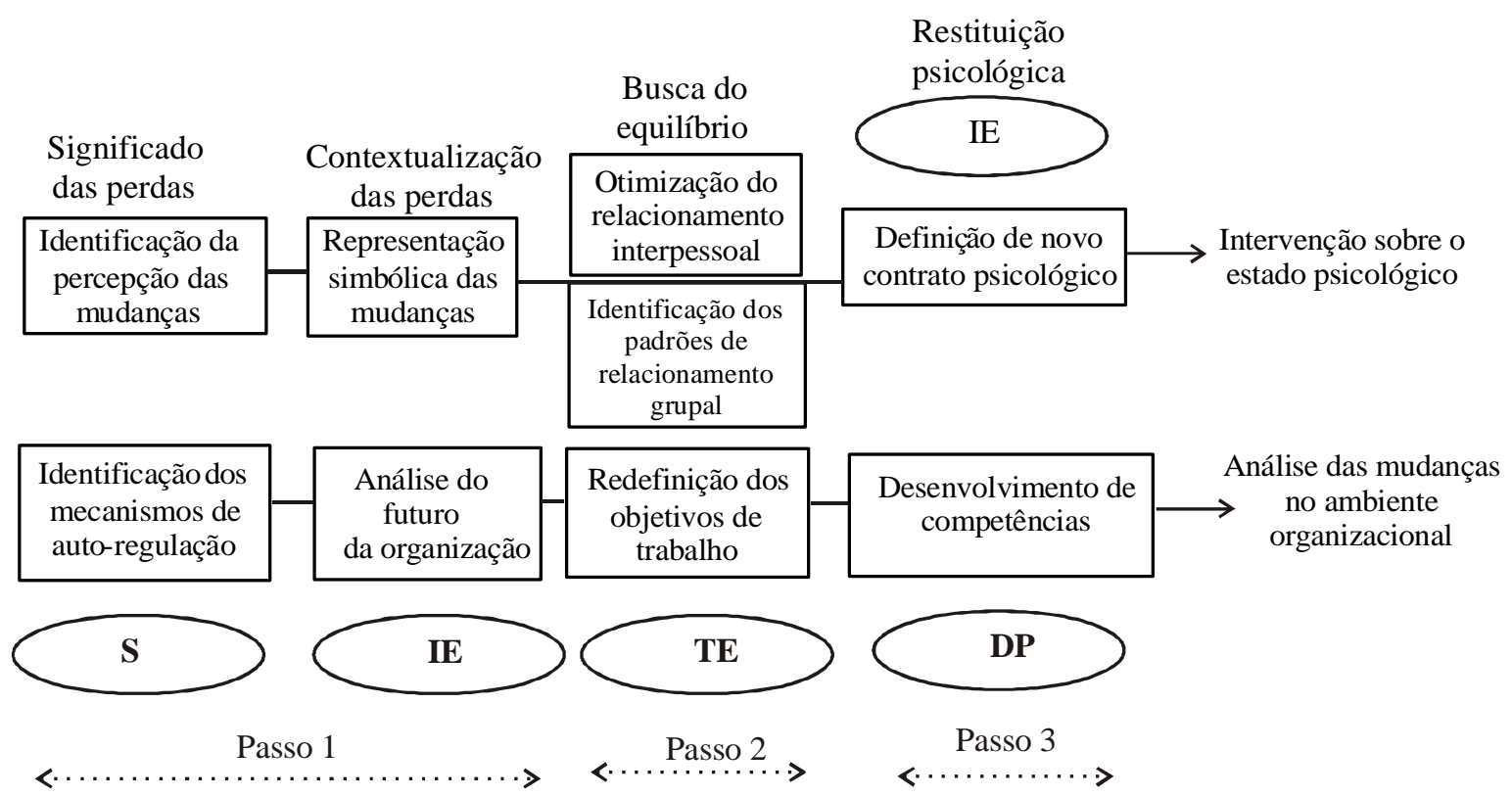

Anexo 11: Modelo de Intervenção Proposto pelo Pesquisador

Dimensões:

S - Saúde

IE - Identificação com a Empresa

TE - Trabalho em Equipe

DP - Desenvolvimento Pessoal 


\title{
NOTAS DE ENSINO
}

\section{Resumo}

O caso trata das perdas simbólicas, vivenciadas pelos funcionários do Banco do Brasil, após a implantação de um plano de reestruturação, que teve como uma das principais ações a criação do primeiro plano de demissão voluntária [PDV]. Apresenta estudo que identifica a percepção que os funcionários tiveram das mudanças, enquanto perda ou ganho, em relação a três dimensões: Práticas de Recursos Humanos, Afiliação a Grupos e Pertinência à Empresa. Também identifica o estado de ânimo destes funcionários bem como a possível existência de sintomas somáticos no período subseqüente às mudanças. $\mathrm{O}$ caso apresenta uma fotografia sem retoques do estado psicológico de funcionários envolvidos em processos de mudança, e serve de subsídio para o desenvolvimento de programas de sensibilização para mudanças organizacionais. Tem os seguintes objetivos educacionais: 1. analisar aspectos psicossociais relacionados aos processos de mudança e à competitividade; 2 . Propiciar aplicação da teoria à prática, solicitando que os alunos desenvolvam um programa de sensibilização para mudanças organizacionais.

Palavras-chave: mudanças organizacionais; gestão de Recursos Humanos; perdas.

\begin{abstract}
The case deals with the symbolic losses experienced by Banco do Brasil employees after the implementation of a restructuring plan, of which one of the main actions was the creation of the first voluntary redundancy plan [VRP]. The study attempts to identify employees' perceptions as Loss or Gain, considering three dimensions: Human Resources Practices, Group Affiliation and Organizational Commitment, as well as employees' moods and the possible existence of somatic symptoms among them in the months leading up to the organizational changes. The case provides a real picture of employees' psychological states involved in change processes, and the research findings can serve as inputs for the development of motivational programs in organizations that are undergoing changes. The case has 2 objectives: 1. to analyze the psychosocial aspects related to organizational changes and competitiveness; 2 . to require students to develop motivational programs for organizations that are undergoing changes, putting theory into practice.
\end{abstract}

Key words: organizational changes; human resources management; grief (losses).

\section{Objetivos Educacionais}

- Os alunos deverão ser capazes de analisar e discutir aspectos psicossociais relacionados aos processos de mudança e à competitividade.

- Os alunos deverão ser capazes de discutir a viabilidade da implantação do modelo proposto pelo pesquisador (Anexo 11), considerando a população de funcionários do Banco e o tempo exigido para que as mudanças acontecessem.

- Os alunos deverão ser capazes de discutir as implicações da implantação do modelo proposto pelo pesquisador (Anexo 11).

- Os alunos deverão discutir a possibilidade de generalização do modelo proposto pelo pesquisador para a aplicação em outras empresas. 


\section{Utilização Recomendada}

O caso pode ser usado em níveis de graduação ou pós-graduação em disciplinas relacionadas a Comportamento Organizacional, Gestão de Pessoas e Planejamento Estratégico. Pode-se explorá-lo especialmente do ponto de vista de competitividade da empresa relacionada a pessoas e do ponto de vista do alinhamento da estratégia da área de Recursos Humanos aos objetivos do negócio.

\section{Conhecimentos que Poderão ser Adquiridos}

Aspectos teóricos e práticos relacionados à Gestão de Pessoas em situações de mudança e de crise organizacional, como: cultura organizacional, relações com os empregados, planejamento de carreira, treinamento e desenvolvimento, desenvolvimento de competências.

Aspectos teóricos e práticos relacionados ao Planejamento Estratégico sob a ótica de teorias de competitividade relacionadas a recursos internos da firma (como a Resource Based View [RBV]).

\section{Problema a Ser Discutido}

O plano de ação proposto pelo pesquisador pode ajudar empresas a implementarem processos de mudanças, fazendo com que os funcionários modifiquem sua percepção delas, encarando-as como possibilidades de ganho, ao invés de perda.

\section{Indicação das Fontes de Obtenção de Dados}

Os dados foram obtidos a partir da tese de doutorado e dissertação de mestrado da autora do caso, disponibilizadas em biblioteca pública para consulta; site do Banco do Brasil.

\section{Plano de Ensino Utilizando o Caso}

O caso deve ser trabalhado em três etapas, conforme abaixo descritas:

1. Primeira etapa: leitura e proposta de resolução individual do caso; análise da viabilidade e das implicações de implantação do plano de ação proposto pelo pesquisador.

2. Segunda etapa: discussão em grupo, dentro ou fora de classe, visando à conciliação das análises feitas individualmente em relação à viabilidade e às implicações de implantação do plano de ação proposto pelo pesquisador. O grupo deverá preparar material para uma apresentação de 10 minutos sobre o caso, utilizando slides, ou outro recurso visual disponível

3. Terceira etapa: Apresentação e discussão em sala de aula das decisões a que chegaram os diferentes grupos em relação à viabilidade e às implicações da implantação do plano de ação proposto pelo pesquisador.

\section{Proposta para a Aula Relacionada à Terceira Etapa de Análise do Caso}

Duração: 120 minutos

Introdução do caso, com breve sumário dele, feito pelo professor.

Apresentação das decisões a que chegaram os diferentes grupos em relação à viabilidade e às implicações da implantação do plano de ação proposto pelo pesquisador. O professor deverá selecionar dois grupos para apresentarem suas análises (20`). Exposição oral com apoio de multimídia (se disponível). 
Abertura de discussão sobre as decisões apresentadas, sendo o professor o moderador. Os grupos que apresentaram suas decisões devem defender sua análise durante esta discussão feita com a classe. O professor deve preparar uma lista prévia de perguntas que induzam a discussão, caso os alunos não apresentem questões logo no início do debate (40’).

Aula expositiva participativa dividida em dois momentos: 1. aula sobre as teorias organizacionais que dão respaldo ao caso (40'), como teorias de competitividade centradas em recursos internos à firma e teorias de desenvolvimento organizacional com foco em gestão de mudanças, o papel da área de Recursos Humanos na gestão do processo de mudança; 2. aula sobre teorias relacionadas aos aspectos psicossociais inerentes ao caso, podendo optar por várias possíveis linhas de discussão: o processo de percepção (enfatizar o fenômeno da interpretação das mudanças, considerando os processos de percepção em níveis individual e grupal); o processo de formação e mudança de atitudes em relação às mudanças (enfatizando as dimensões afetiva, cognitiva e comportamental da atitude; atitudes e formação de crenças; atitudes e comportamentos); os estados psicológicos de luto (ciclo do luto; luto patológico); a ruptura do contrato psicológico.

Resumo e fechamento das discussões dos casos, entrelaçando teoria e prática (20’).

\section{Roteiro Proposto aos Alunos para Análise do Caso (Etapa Individual)}

1. Qual era a situação dos funcionários do Banco na época do levantamento dos dados? Como eles percebiam as mudanças em termos de ganho ou perda? (ver Anexos 4, 5 e 6 ).

2. Como o Programa de Demissão Voluntária [PDV] poderia afetar o estado de ânimo dos funcionários que não aderiram a ele? (ver Anexos 7, 8 e 9).

3. Poderia haver conflito entre o ponto de vista dos que estavam entrando no Banco com o dos funcionários que já estavam no BB por ocasião do PDV? Isto se poderia refletir no desempenho?

4. Olhando o modelo de correlações apresentado pelo pesquisador externo, quais são as variáveis importantes do caso? Há relação suposta de causa e efeito entre elas?

5. Analise o plano de ação proposto pelo pesquisador (Anexo 11) para preparar pessoas para mudanças organizacionais. Quais são os aspectos mais relevantes do plano? Como trabalhar com os dois eixos de intervenção propostos, de maneira concomitante? Quais recursos seriam necessários para implantação do plano de ação? Como implantar as ações propostas para uma população de quase 18.000 pessoas? Quais as implicações possíveis decorrentes da adoção ou da não adoção do plano? Leve em consideração critérios de: gasto com as ações propostas; tempo previsto para implantação de cada ação; efeito esperado; mensuração de resultados da ação proposta (ver Anexo 10, que mostra as correlações entre as dimensões pesquisadas); alinhamento da ação às estratégias do negócio.

6. Analise a possibilidade de generalização deste plano de ação para outras empresas que estejam passando por processos de mudança e que tenham o mesmo porte do Banco do Brasil. O plano pode adequar-se às empresas de outros segmentos ou de outro porte?

\section{Análise da Autora (Considerando a Possibilidade de Generalização do Plano de Ação)}

Discussão das duas linhas de atuação propostas no modelo do pesquisador:

1. Foco na análise dos aspectos psicossociais relacionados às mudanças, como a percepção delas, os sentimentos envolvidos, a mudança dos papéis e da configuração das equipes e trabalho; o contrato psicológico; ver no Anexo 11 o primeiro eixo proposto para intervenção. 
1.1. Identificação da percepção das mudanças (relacionada à dimensão Saúde) sob a ótica da teoria da Psicologia Social: explorar a questão da interpretação que se faz das mudanças, apoiada em crenças e valores pessoais; enfatizar o estado de estresse relacionado ao medo à mudança. (ver as correlações apresentadas no Anexo 10).

O processo de percepção envolve a captação dos indícios de mudança e a interpretação que se faz do conjunto desses indícios e das perspectivas apresentadas pela organização. Para alguns, a mudança pode ser interpretada como grande oportunidade de ascensão ou de desenvolvimento. Para outros, ela representa a incerteza e o risco, notadamente quando representam, para aquele que as vive, situações de ruptura irreversível, consideradas pequenas mortes simbólicas e, portanto, de perda (ver os Anexos 4, 5 e 6, que mostram a frequência da percepção de perda). O que determina a interpretação são as crenças pessoais em relação ao novo, à incerteza, ao risco. Se a mudança é considerada como estímulo aversivo e irreversível, o sentimento dominante é o de medo e, consequentemente, de ansiedade, afetando a saúde física e psicológica dos sujeitos com ela envolvidos. Isto pode ser visto no Anexo 8, que mostra os sentimentos escolhidos como predominantes no estado de ânimo dos sujeitos no ano anterior à pesquisa, e três anos após as mudanças (ver legenda do Anexo 8). O Anexo 9 mostra os sintomas somáticos relacionados a estresse; conforme se apresenta no relato do caso, vários deles eram declarados como presentes por grande percentual dos funcionários pesquisados.

1.2. Representação simbólica das mudanças (relacionada à dimensão Identificação com a Empresa): discutir a questão da identidade pessoal, usando como padrão de identificação a empresa e analisar os problemas decorrentes disto (a empresa vista como grande família, a perda de identidade na comunidade pela perda do emprego); analisar a perda da identidade pessoal e do comprometimento em relação à empresa, visto que as rupturas podem ser percebidas como abandono.

$\mathrm{O}$ sentimento de abandono pode ser analisado pela ruptura do contrato psicológico existente entre empregado e empregador. No caso do $\mathrm{BB}$, todos os funcionários haviam ingressado por concurso público e muitos acreditavam que o contrato de trabalho jamais seria rompido, embora fosse regido pelas leis da CLT. Assim, a sinalização da possibilidade de demissão era sentida como uma ruptura do mito da grande família e de uma mudança nas regras.

Outra questão importante é que os funcionários tinham uma imagem forte na comunidade, decorrente de seu status como funcionário do BB. Havia, na época, uma imagem de que ser bancário do $\mathrm{BB}$ era uma profissão de prestígio, e não uma ocupação. $\mathrm{O}$ funcionário tinha um salário relativamente acima do mercado, o que lhe garantia bens econômicos e posição social.

1.3. Otimização do relacionamento interpessoal e identificação dos padrões de relacionamento grupal (dimensão trabalho em equipe): discutir a formação de grupos, resolução de conflitos intraequipes etc. e sua importância para a reorganização do trabalho.

No momento em que ocorreram as demissões, muitas equipes ficaram desfalcadas; em algumas áreas houve perda de expertise. Nesse momento, novas equipes precisavam ser formadas e, para tal, era preciso pensar em novo arranjo do processo de trabalho, reunindo em uma mesma equipe pessoas de diferentes áreas e formações. O que poderia ser uma vantagem competitiva poderia ser uma desvantagem, se não se fizesse um esforço de integração e de ressignificação do trabalho dentro do novo modelo de atuação do BB, mais competitivo e com foco em resultados. O Anexo 10 mostra as correlações existentes entre as dimensões. Ver as correlações de trabalho em equipe com as demais dimensões.

1.4. Definição de novo contrato psicológico (dimensão identificação com a empresa): discutir as questões relacionadas à cultura da organização, em termos de desenvolvimento de crenças e valores que apóiem o novo modelo de empresa; abordar a questão da formação de atitudes favoráveis à mudança. 
Naquele momento havia a necessidade de se discutir a nova missão da empresa, os valores decorrentes da mesma e as predisposições esperadas ou, em outras palavras, as atitudes que eram consonantes com o novo modelo da empresa. A mudança de atitudes não ocorre em curto prazo e são necessárias ações específicas para a sensibilização dos empregados. A empresa pode controlar os comportamentos, que são diretamente observáveis, mas não as atitudes. Se houver dissonância cognitiva, o comportamento desejado pode não se manter no médio ou longo prazo.

2. Foco na análise das mudanças no ambiente organizacional e da necessidade de realinhamento de processos, cargos e competências. Ver no Anexo 11 o segundo eixo proposto para intervenção.

2.1. Identificação dos mecanismos de autorregulação (dimensão saúde): discutir as teorias de competitividade - sugere-se a RBV, na qual as pessoas são vistas como recursos da firma; explorar a possível perda de valor para o negócio, se persistisse o modelo de gestão anteriormente existente.

Se pessoas são recursos valiosos, raros, inimitáveis, a empresa precisa mantê-las, considerando que sua perda envolve diminuição de valor. Neste aspecto, pode-se analisar quais práticas de Gestão de Pessoas são adequadas para a valorização do capital humano; acredita-se que as ações de treinamento/desenvolvimento e avaliação de desempenho fossem as principais ações a serem valorizadas naquela situação em que o BB se encontrava após as mudanças.

2.2. Análise do futuro da organização (dimensão identificação com a empresa) e do papel das pessoas na construção da nova empresa.

Analisar os pontos fortes e fracos do BB em face dos demais concorrentes e o papel das pessoas em situações em que a qualidade do serviço seja um dos principais fatores de diferenciação.

2.3. Análise das competências pessoais exigidas, identificando a necessidade de mapeamento do possível gap entre as competências existentes e as exigidas.

2.4. Análise da necessidade de redefinição dos objetivos de trabalho, coerentes com as competências essenciais da empresa atualmente exigidas.

3. Possibilidade de generalização dos resultados.

O Anexo 11 mostra uma estrutura prevista para intervenção em situações de mudança. Cada passo apresentado se refere a dimensões a serem trabalhadas. As propostas de intervenção não têm conteúdos específicos, porque estes dependem de aspectos típicos de cada organização. A generalização do modelo depende da constatação, na organização sob análise, da existência de situações de mudança que sejam percebidas como situações de perda. Neste caso, o processo de luto é a resposta psicológica natural e esperada; assim, a intervenção proposta se adapta, pois está baseada na análise do processo de luto.

\section{BIBLIOGRAFIAS RECOMENDADAS}

Barney, J. (2002). Gaining and sustaining competitive advantage (2a ed.). New Jersey: Prentice Hall.

Becker, E. (1995). A negação da morte (2a ed.). Rio de Janeiro: Record.

Bittencourt, C. (Org.). (2004). Gestão contemporânea e pessoas - novas práticas, conceitos tradicionais. Porto Alegre: Bookman.

Bowlby, J. (1985). Perda - tristeza e depressão. São Paulo: Martins Fontes. 
Cameron, K. S., \& Quinn, R. E. (1999). Diagnosing and changing organizational culture: based on the competing values framework. Reading, MA: Addisson-Wesley Publishing Company, Inc.

Cohen, A. R., \& Fink, S. L. (2003) Comportamento organizacional - conceitos e estudos de caso. Rio e Janeiro: Campus.

Hofstede, G. (1998). Attitudes, values and organizational culture: distangling the concepts. Organization Studies, 19(3), 477-493.

Ivancevich, J. M. (2008). Gestão de recursos humanos. São Paulo: Mc Graw-Hill.

Novaes, M. H. (1995). Conquistas possíveis e rupturas necessárias. Rio de Janeiro: Grypho.

Pereira, M. H. (1994). A psicoterapia em situações de perdas e lutos. São Paulo: Editorial Psy II.

Robbins, S. (2005). Comportamento organizacional. São Paulo: Pearson.

Sievers, B. (1994). Work, death and life itself. New York: Walter de Gruyter. 